\title{
Breast Granular Cell Tumor
}

National Cancer Institute

\section{Source}

National Cancer Institute. Breast Granular Cell Tumor. NCI Thesaurus. Code C40400.

A usually benign neoplasm that arises from the breast. It presents as a single, firm, and painless mass. It is characterized by the presence of neoplastic cells with eosinophilic granular cytoplasm. 